Meta

Journal des traducteurs

Translators' Journal

\title{
Translating Cultures: A Linguistic Reading of A Dream of Red Mansions
}

\section{Jianshe $\mathrm{Wu}$}

Volume 53, numéro 3, septembre 2008

URI : https://id.erudit.org/iderudit/019237ar

DOI : https://doi.org/10.7202/019237ar

Aller au sommaire du numéro

\section{Éditeur(s)}

Les Presses de l'Université de Montréal

\section{ISSN}

0026-0452 (imprimé)

1492-1421 (numérique)

Découvrir la revue

Citer cet article

Wu, J. (2008). Translating Cultures: A Linguistic Reading of A Dream of Red Mansions. Meta, 53(3), 507-527. https://doi.org/10.7202/019237ar
Résumé de l'article

Cet article tente, dans une perspective linguistique, en utilisant la notion d'événement de déplacement, de présenter une analyse contrastive d’une série de traductions d'une même oeuvre, dans une même langue mais dans des versions différentes. En analysant le même objet, nous accordons une grande importance à l'impact du texte-source aussi bien qu'à l'impact du traducteur sur le texte-cible. Comme le suggère Talmy $(1985 ; 2000)$, les différentes langues contiennent différents systèmes de verbes de mouvement, qui pourraient être décrits par un modèle universel de ces éléments sémantiques : figure, fond, mouvement, trajectoire et manière. Ainsi l'anglais et le chinois peuvent être tous les deux classifiés comme langues à satellites (d'un autre côté, on trouve les langues à cadre verbal) (Talmy 2000). Et dans ce sillage, de nombreuses recherches sur différentes langues s'épanouissent dans l'espoir de valider l'hypothèse de la " relativité linguistique ".

Cependant, jusqu'ici, l'adoption linguistique de la notion d'événement de déplacement n'a pas été trouvée en analysant l'impact possible de la source et du traducteur en filigrane dans les traductions dans une même langue mais dans des versions différentes. Dans cette pespective, cet article, en utilisant ce concept sémantique, tente d'analyser cet impact mentionné ci-dessus comme il est représenté chez David Hawkes, John Minford, et Xianyi Yang et Galdys Yang, à la lumière de leurs traductions respectives du Rêve dans le pavillon rouge.
Ce document est protégé par la loi sur le droit d'auteur. L'utilisation des services d'Érudit (y compris la reproduction) est assujettie à sa politique d'utilisation que vous pouvez consulter en ligne.

https://apropos.erudit.org/fr/usagers/politique-dutilisation/ 


\title{
Translating Cultures: A Linguistic Reading of $A$ Dream of Red Mansions ${ }^{1}$
}

\author{
JIANSHE WU \\ Beijing International Studies University, Beijing,China \\ wujs05@mails.tsinghua.edu.cn
}

\section{RÉSUMÉ}

Cet article tente, dans une perspective linguistique, en utilisant la notion d'événement de déplacement, de présenter une analyse contrastive d'une série de traductions d'une même œuvre, dans une même langue mais dans des versions différentes. En analysant le même objet, nous accordons une grande importance à l'impact du texte-source aussi bien qu'à l'impact du traducteur sur le texte-cible. Comme le suggère Talmy $(1985 ; 2000)$, les différentes langues contiennent différents systèmes de verbes de mouvement, qui pourraient être décrits par un modèle universel de ces éléments sémantiques: figure, fond, mouvement, trajectoire et manière. Ainsi l'anglais et le chinois peuvent être tous les deux classifiés comme langues à satellites (d'un autre côté, on trouve les langues à cadre verbal) (Talmy 2000). Et dans ce sillage, de nombreuses recherches sur différentes langues s'épanouissent dans l'espoir de valider l'hypothèse de la «relativité linguistique ».

Cependant, jusqu'ici, l'adoption linguistique de la notion d'événement de déplacement n'a pas été trouvée en analysant l'impact possible de la source et du traducteur en filigrane dans les traductions dans une même langue mais dans des versions différentes. Dans cette pespective, cet article, en utilisant ce concept sémantique, tente d'analyser cet impact mentionné ci-dessus comme il est représenté chez David Hawkes, John Minford, et Xianyi Yang et Galdys Yang, à la lumière de leurs traductions respectives du Rêve dans le pavillon rouge.

\section{ABSTRACT}

This paper attempts to present a contrastive analysis of sets of translation of the same work, in the same language but of different versions, from a linguistic perspective, by means of Motion event. In analyzing the same, we attach great importance to the source text effect as well as the translator effect on the target text.

As suggested by Talmy $(1985,2000)$, different languages contain different systems of verbs of motion, which could be described by a universal pattern of its semantic elements: Figure, Ground, Motion, Path and Manner. Accordingly English and Chinese could be both classified as satellite-framed languages (the other alternative is verb-framed languages) (Talmy 2000). And in this wake, many researches flourish in different language contexts in hopes of validating the "linguistic relativity" hypothesis.

However, up to now, a linguistic adoption of Motion event has not been found in analyzing the possible source and translator effects underlying the translation works in the same language but of different versions. In this view, this paper tends to utilize this semantic category to analyze the above-mentioned effects as represented in David Hawkes, John Minford, and Xianyi Yang and Galdys Yang, in the light of their respective translatings of A Dream of Red Mansions (or the Story of the Stone).

\section{MOTS-CLÉS/KEYWORDS}

motion event, source text effect, translator effect, A Dream of Red Mansions, cultures 


\section{Introduction}

As pointed out by Bassnett and Lefevere (1990), “The object of (translation) study has been redefined; what is studied is the text embedded in its network of both source and target cultural signs and in this way Translation Studies has been able both to utilize the linguistic approach and to move out beyond it." (2001 [1998]: 123) This shift of emphasis is dubbed as "the cultural turn" in translation studies. In 1998, Bassnett claims that "Translation studies has moved on from endless debates about 'equivalence' to discussion of the factors involved in text production across linguistic boundaries." (2001 [1998]: 133) Actually, their insightful observation leads us to a greater awareness of what could be covered by translation studies and at the same time, provides us additional methodological solutions for translation studies. In the ensuing decades, translation studies flourished in the wake of "the cultural turn." It is well justified in the announcement made by Gentzler (2003 [2001]: 194): “Translation studies scholarship over the last three decades has build up a critical mass of scholarship, data that any cultural studies scholars investigating intercultural movement should consult."

Nevertheless, embarrassingly, translation studies are still viewed as "a house of many rooms" (Neubert and Shreve 1992). Hatim also admits that "there remains a great deal of uncertainty over the status of translation studies as a discipline" (Hatim 2005[2001]: 8). Confronted with this dilemma, Wang (2006) has proposed three clear-cut orientations as follows for it to develop into an independent discipline, based on a combination of theories and resources from a variety of disciplines:

- Translation studies from a comparative-literature angle. Many researchers of comparative literature, such as Lefevere and Ouyang, could serve as forerunners in this respect;

- Translation studies from a linguistic perspective. We should return to the text itself; (For example, different translation works or different versions of the canonical work could be re-analyzed from a linguistic viewpoint.)

- Translation studies under the cultural context. We could focus on theory building or elaboration.

(Wang 2006: 42-43, translated by the present author)

Although his observations could also be traced in many scholars' writings, such a systematic proposal points to the necessity of establishing a pluralistic and open framework for translation studies. For a long time, habitually or subconsciously, we have been upholding a single established theoretical framework as a tool of our solution to those translation problems or as a measure of assessment. And what Wang has proposed may throw light upon this: Is it better to have such a pluralistic and open framework? This question awaits more exploration. (According to Ladmiral, we'd better exercise pluralism in translation studies. [Ladmiral 1994, cited in Xu et al. 2001: 93-94])

Based on this understanding, we are less confused and attempt in this paper to "return to the text itself" in the light of linguistics. Methodologically, we have benefited a lot from Hatim. As he says, "comparing and contrasting two or more languages at various levels of linguistic description has interacted with translation studies in two basic ways: 
- It has provided explanations for and solutions to problems encountered in translation practice (Nida 1964);

- It has in turn received from translation a range of theoretical and practical insights, as well as actual data and specific information (James 1980).

(Hatim 2005[2001]: 81)

Combining Wang's insightful observation with Hatim's revealing suggestions, we shall establish a contrastive analysis on different versions (but in the same language, i.e., English) of a Chinese classical work, A Dream of Red Mansions (or the Story of the Stone), translated respectively by Hawkes, Minford and Xianyi Yang \& Gladys Yang (hereinafter called Yang since we assume that Xianyi Yang has played a dominant role in translating the work, as evidenced in his interview with a news reporter ${ }^{2}$ ). Its purpose lies in what Baker has thoughtfully suggested: "translated texts tend to flaunt certain conventions and overuse certain features known to be characteristics of style in the target language"(Baker 1993: 244). That is, we are seeking the cultural effects underlying the translated texts, which result respectively from translators' linguistic and cultural backgrounds (hereinafter called Translator effect) and from the adaptation to linguistic structures in source texts (hereinafter called Source effect). We believe Wang's insightful observation, Hatim's revealing suggestions and Baker's foreseeable hypotheses could be substantiated (or falsified) and further investigated in the light of such linguistic elements as Motion event. As far as the discipline of translation studies is concerned, what we are trying to say by our study is no more than "Here is another way that seems to work."

\subsection{Motion event}

First, we will briefly introduce what the linguistic term Motion Event means. The "event" has been identified as a basic building block of language and cognition by current cognitive linguistic research (e.g., Goldberg 1998; Talmy 2000). In this study, we focus on a particular type, i.e, Motion event, "a situation containing motion and the continuation of a stationary location alike" (Talmy 2000: 25). The basic Motion event consists of one object (the Figure) moving or located with respect to another object (the reference object or Ground). It is analyzed as having four components: besides Figure and Ground, there are Path and Motion. The Path is the path followed or site occupied by the Figure object with respect to the Ground object. The component of Motion refers to the presence per se of motion or locatedness in the event. For example: "John climbed out of the tree." The motion event is thus directed in a descending path, in a grasping manner, from a source defined as the tree to an unspecified goal. The figure is designated by a noun (John), the main verb describes a manner of motion (climb), a particle ("satellite") tells the path (out), and a prepositional phrase gives the source (of the tree).

Here, we follow Talmy's $(1985,2000)$ typological approach to the linguistic encoding of events. He has proposed a two-way split between the languages of the world according to the way the core feature of an event is expressed linguistically. Those languages encoding the core feature in the verb are labeled as verb-framed languages, while the others encoding the core features in a "satellite" to the verb (e.g., particles, as in English, prefixes, as in Russian), satellite-framed languages. Here are some examples: 
- Satellite-framed languages:

Germanic: Dutch, English, German, Icelandic, Swedish, Yiddish;

Slavic: Polish, Russian, Serbo-Croatian, Ukrainian;

Finno-Ugric: Finnish;

Sino-Tibetan: Mandarin.

- Verb-framed languages

Romance: French, Galician, Italian, Portuguese, Spanish;

Semitic: Arabic, Hebrew;

Turkic: Turkish;

Japanese;

Sign Languages: American Sign Language, Sign Language of the Netherlands.

To make it clearer, below is a well-known example presented by Talmy, in which the former is regarded as a V-language with "enter" as a path verb, while the latter is treated as an S-language with "into" indicating the path:

- La botella entró flotando a la cueva (Spanish)

'the bottle entered floating to the cave'

- The bottle floated into the cave. (English)

(Talmy 2000)

Now we will turn to Mandarin pe ser.

\subsection{Mandarin Chinese in Talmy's framework}

Mandarin Chinese has been categorized as an S-language by Talmy, which is a serialverb language in which each verb in the series is morphologically unmarked and monosyllabic. Talmy (2000) considers the manner verb in the series to be the main verb and the path verb to be a satellite, because path verbs often do not function as full verbs and there is a small, closed set of path verbs.

However, as observed by Slobin (2004a), the two elements tiao jin 'jump enter' in the following Mandarin Chinese are both verbs (both 'enter' alone, and 'jump enter,' are options used here. For the former, 了 (le3 'le'), a perfective aspect marker, should be added after 'enter.'):

- 他 跳 进 河
Ta1 tiao4 jin4 he2
He jump enter river
(He jumped into the river)

Such constructions are highly frequent in Mandarin Chinese. In his continuous study of "Frog Story," Slobin (2004a) observes they are used by $40 \%$ of Mandarin speakers to narrate the owl's emergence ("the owl's emergence" is one event in the "Frog Story." For details, see Bergman and Slobin 1994). He holds that the Mandarin and Thai data raise a problem for Talmy's treatment of path verbs as satellites in serial-verb languages and thinks it may be most appropriate to treat serial-verb languages as a third typological category with regard to motion events. He (2004a) proposes that a third type, Equipollently-framed languages, be added to include serial-verb languages and other types of languages in which both manner and path are expressed by "equipollent" elements - that is, elements that are equal in formal linguistic terms, and appear to be equal in force or significance. 
However, according to Shen's study on Chinese "Verb + Complement" structure, he tends to vote for Talmy's classification with certain caution (Shen 2003: 22). Taking all these findings into consideration, and for our research purpose, we disregard such discrepancy between the above-mentioned different classifications and still treat, as Talmy does, the complement verb in Mandarin Chinese, “进jin4(enter)" in the above example as a satellite particle. This treatment is strictly followed in the forthcoming analysis.

\subsection{Background for Relating Motion Events in Translation}

The linguistic elements often conflate several conceptual notions, and some notions may be mapped across several linguistic elements. This understanding lends a great hand in exploring the possible cultural differences across languages by analyzing those linguistic elements in different versions of the same work in a contrastive way.

In this respect, Guillmin-Flesher (1981, cited in Xu et al. 2001: 13-14) has contributed a lot in blazing a new trail. The writer pinpoints many sentences from five main English translation works of Madame Bovary (Flaubert 1857), and analyzes such linguistic structures as aspect, tense, number as well as their corresponding shifts under different contexts. He attempts to illustrate that, the similarity among those linguistic categories is not compulsory for their functional equivalence, and that such extra-linguistic factors as the contexts, the translators' attitudes and other social, cultural and historical influences underlying the source and target texts in question should invite more of our attention.

In the same vein, Motion event could be effectively employed by this kind of analysis in translation studies. Slobin $(1996,1997)$ examines the consequences of the typological difference as shown in the narrative styles of both languages. Looking at a number of English and Spanish novels and their translations, he concludes that English has a much higher number of motion verbs which incorporate manner than Spanish. Relating this to Talmy's verb typologies, he mentions that "S-languages will have a larger and more diverse lexicon of manner verbs in comparison with V-languages" (Slobin 1997: 458). In addition, Slobin notices that this difference in the number and nature of the lexicon of manner verbs has posed particular problems for translators in both directions. For instance, in Slobin (1996) he finds out that only $51 \%$ of English manner verbs are translated into Spanish manner verbs. In the remaining cases, information about manner was either omitted or neutralized. Going from Spanish into English, he observes that translators frequently add manner information which is not lexically incorporated in the Spanish motion verb.

In the following studies, Slobin has attempted to consider how many Ground elements can be expressed in a single clause (Slobin 1996, 1997, 2004b) by analyzing motion events in The Hobbit (Tolkien 1937), written in English, with its translations in the other 10 languages, into Figure, Motion, Path, Manner, and Ground. Tolkien is found to use 26 different types of manner verbs. Translations into the four satellite-framed languages use an average of 25.6 types - that is, matching the original. (Russian actually surpasses the original, with 30 types.) However, the verb-framed translations use an average of 17.2 types, with only Italian approaching Tolkien's diversity (Slobin 2004b). 
Apart from Slobin's pioneering work, Ana Rojo and Javier Valenzuela (2001), while dealing with verbs of saying, found that Spanish translators tend to add information, using more specific verbs. This indicates that translators do not look for isolated lexical equivalents of each verb. They rather take into account the interactional frame which the verb activates, the whole contextual frame that is built throughout the narration, and knowledge about interactional frames stored in their long-term memory. Translators tended to supply additional information which was taken from their evaluation of the global interactional frame, regardless of the verb used in the original version.

Oh's study is not directly concerned with translation studies, though, it is still informative for those who are interested in carrying out a contrastive analysis between Korean and English. Oh (2003) shows that manner-of-motion verbs are more heavily used in novels by writers of English (a satellite-framed language) than by those of Korean (a verb-framed language). Another similar attempt was made by Chen (2005) to examine how Chinese writers describe Motion events involving the movement of a character or characters from one place to another in creative fictions. It is observed that the typological and discourse characteristics of Motion event descriptions is shown both in oral narrative and in written narrative in Chinese. Overall, the research suggests that while Chinese writers show the satellite-framed language tendency to encode more manner details, they also show the verb-framed language tendency to encode fewer path details.

Among them, Ozcaliskan \& Slobin's research is revealing to our study in terms of both their findings and methodology. In the light of motion "episodes" and "alternative lexical means" (see below for further information), they (2003) examine the expression of manner of motion in novels in Turkish (a verb-framed language) and English, and observe the same typological contrast in motion verb use. The nine novels written in English include more manner verbs (51\% of all motion verbs) than nine novels written in Turkish (30\%). Compared with English novels, Turkish mainly relies on path verbs (59\% versus $27 \%$ ) in describing motion events. In addition, novels in these two languages also differ sharply in the diversity of manner verbs used (82 types in English versus 32 types in Turkish). When alternative means of conveying information about manner of movement are considered, it is found that "Turkish speakers use these means mainly to add manner information to basic motion event descriptions, apparently compensating for what they cannot easily encode at the level of motion verb constructions," while "English speakers use such means predominantly to elaborate or augment the manner that has already been encoded by the verb." (Ozcaliskan and Slobin 2003: 268)

\subsection{Justification of this study}

As cognitive linguistics believes, the relationship between language and reality is mediated by human cognition. Human categories and constructions as realized in language are neither objectively manifested in the physical world nor external to human beings. They are largely motivated by our bodily and mental experiences of the world and the ways we perceive and conceptualize the world. We believe the same is true with the process of translating. Just as the current translation theory holds, each translator will have a different interpretation or rewriting of the original text. This point is illustrated well in Bhabha's the Location of Culture: 
Translation is the performative nature of cultural communication. It is language in actu (enunciation, positionality) rather than language in situ (enonce or propositionality). And the sign of translation continually tells, or 'tolls' the different times and spaces between cultural authority and its performative practices. The 'time' of translation consists in that movement of meaning, the principle and practice of a communication that, in the words of de Man 'puts the original in motion to decanonise it, giving it the movement of fragmentation, a wandering of errance, a kind of permanent exile.' (Bhabha, [2004]1994: 326)

Actually, here Bhabha is describing the performativity of translation as the staging of cultural difference under the influence of Benjamin's concept of "foreignness." Such "foreignness" could be easily perceived here in terms of "the source effect and translator effect," because it is assumed that translators strive to maintain or enhance the force and vividness of the target text, thus the use of translations provides a particularly stringent test of each language's capacities (within the limits, of course, of the skills of individual translators). The translation task thus gives us a window into the maximum possibilities of a language, as it strives to adapt to the demands of a source language. It applies both to native translators, like Hawkes and Minford, and to foreign ones, like Yang. Thus, by analyzing the target text, it is possible to detect "foreignness," i.e., the source and translator effects as a reflection of the abovementioned efforts.

As readers may have noted, the previous relevant researches explore the possibility of detecting the typological differences across languages from different perspectives. However, the possible source effect and translator effect between sets of translation of the same work in the same language but of different versions fail to attract the researchers' attention. Up to now, we haven't found a similar study by means of Motion event available at present, though a contrastive analysis between English and Chinese is far from fresh. Accordingly, in this study we will present our analysis on three different translation works of A Dream of Red Mansions (《红楼 梦》) $)^{3}$ (respectively by David Hawkes, John Minford and Yang).

It should be noted that there are very few relevant findings to serve as a frame of reference for our following analysis. Thus, it is necessary for us to include the other two similar samples based on Mao's Spring Silkworms ${ }^{4}$ and Brown's The Da Vinci Code, ${ }^{5}$ to provide us with some data which are compulsory for our analysis. (These three above-mentioned works are selected partly because they are all well known to Chinese and perhaps also to those foreigners who are interested in Chinese, partly because the linguistic features of Chinese employed in them may represent different stages of Vernacular Chinese development: before 1919, after 1919 but before 1949 (the founding of P.R.China), and contemporary; but the linguistic features of English in use here could all be regarded as identical.)

\section{Methods}

As readers may have noted, in this study we comply with Ozcaliskan and Slobin's (2003) sampling method and procedure in general in order to compare our data with their findings to certain extent. 


\subsection{Sample}

The sample consists of six sub-samples, with two Chinese sub-samples from the original work of A Dream of Red Mansions and four English sub-samples of their respective translations, and each is composed of 20 "episodes," which is defined as "the movement of a major protagonist, beginning from a stationary position and continuing to move until arriving at another stationary position where a plot-advancing event occurs." (Ozcaliskan and Slobin 2003: 260) (Following this definition, we just left these "verbs of locatedness" behind without treatment.)

For the first Chinese sub-sample (Chinese 1), 20 "episodes" are chosen from the Chinese source text every two chapters, starting from Chapter One. And then Hawkes' and Yang's (Yang 1) corresponding translations are singled out to serve as the next two English sub-samples. And for the second Chinese sub-sample (Chinese 2), each "episode" is chosen every chapter, starting from Chapter One Hundred. Accordingly, Minford's and Yang's (Yang 2) sub-samples are established in the same way as two other sub-samples.

Then, each episode is divided into several "clauses" containing Motion event, which is defined as "any unit containing a unified predication, whether in the form of a verb or adjective (Bergman and Slobin 1994)" for English and "any unit containing a unified predication, whether in the form of a noun, verb, adjective or phrase (Wang Li 1985; Liu Shuxing 20026)" for Chinese. Their respective number of clauses is listed as follows:

TABLE 1

The Number of Clauses in Each Sub-sample

\begin{tabular}{|l|l|l|l|l|l|l|}
\hline & Chinese1 & Hawkes & Yang 1 & Chinese2 & Minford & Yang2 \\
\hline Clause & $88 / 88$ & $99 / 63$ & $80 / 76$ & $121 / 121$ & $121 / 78$ & $105 / 69$ \\
\hline
\end{tabular}

* The number before the slash includes those non-Motion-event clauses but excludes those left untranslated in translation works. And the number after the slash indicates the corresponding Motion-event clauses.

Apart from Ozcaliskan and Slobin's research, there are no sufficient findings to act as a frame of reference. We therefore examine, in the same way, the other four similar sub-samples for purpose of reference, one between $\mathrm{Da}$ Vinci Code (by Dan Brown) and its Chinese translation (by Zhu et al.), and the other between 春虫 (chun1 chan2) 'Spring Silkworms' (by Mao Tun) and its English translation (by Sidney Shapiro). Their respective number of clauses is also presented here:

TABLE 2

The Number of Clauses in Mao's and Brown's Samples

\begin{tabular}{|l|l|l|l|l|}
\hline & Brown & Zhu et al. & Mao & Shapiro \\
\hline Clause & $107 / 84$ & $133 / 87$ & $105 / 105$ & $118 / 89$ \\
\hline
\end{tabular}

* The number before the slash includes those non-Motion-event clauses but excludes those left untranslated in translation works. And the number after the slash indicates the corresponding Motion-event clauses. 


\subsection{Procedure}

Each clause containing Motion event in our sample is coded for type of motion description in terms of the following conceptual categories, according to the motion coding system extended and elaborated by Talmy's $(1985,2000)$ analysis (He also considered the factor of self- versus caused-change of location; we don't include such further elaboration in our analysis. That is, the motion elements in "fled" and "expelled" present in he fled from the room and he was expelled from the room are regarded as the same):

- a moving Figure

- the fact of Motion

- Path of motion

- Manner of motion, and

- the physical Grounds with respect to which the figure is moving.

Various alternative lexical means are also available in both English and Chinese for communicating information about manner of movement in describing Motion event. According to Ozcaliskan \& Slobin, it is possible that V-language speakers make frequent use of such alternative means to encode manner of motion, thus compensating for the relative difficulty of encoding both path and manner in their linguistic expressions. For this sake, those three parameters are also included in our analysis (see Ozcaliskan and Slobin 2003).

- adverbial expressions that describe or suggest manner of movement - descriptions of internal state or physical condition of a moving entity - descriptions of features of the physical setting that could influence manner of movement

\section{Results and Discussions}

Analysis at the level of motion verb uses, alternative lexical means, path and figure suggests a clear culturally typological difference between sets of translations. In the light of both the source text effect and the translator effect, we intend to present a plausible explanation for such deviation. At the same time, ground references and segmenting comparison only partially demonstrate such difference. A clear-cut description invites further evidence.

\subsection{Verbs of Motion}

After further coding, the categories of Motion verbs included in the analysis are " $\mathrm{V}$ : manner (manner verbs), V: path (path verbs), V: neutral (verbs with no manner or path), V+V: manner (sub) (subordinated manner verbs)"(see Ozcaliskan and Slobin 2003). Here we add one more dimension, i.e., V: deixis, which includes all deixis verbs used in both source and target texts, i.e., "go" and "come" in English and “来 (lai2) 'come”" and “去(qu4) 'go'” in the Chinese source text, whether it is employed as a verb or a complement verb. The result is presented as follows, with English and Turkish data from Ozcaliskan and Slobin's findings (2003: 262): 
TABLE 3

Percentage of Motion Verb Use

\begin{tabular}{|l|l|l|l|l|l|}
\hline & V: manner & V: path & V: neutral & $\begin{array}{l}\text { V+V: manner } \\
(\mathbf{s u b})\end{array}$ & V: deixis \\
\hline English & $51 \%$ & $27 \%$ & $20 \%$ & $2 \%$ & \\
\hline Turkish & $30 \%$ & $59 \%$ & $7 \%$ & $4 \%$ & \\
\hline Chinese $1 / 2$ & $11 \%$ & $49 \%$ & $40 \%$ & $0 \%$ & $59 \%$ \\
\hline $\begin{array}{l}\text { Hawkes \& } \\
\text { Minford }\end{array}$ & $26 \%$ & $30 \%$ & $42 \%$ & $2 \%$ & $23 \%$ \\
\hline Yang $1 / 2$ & $28 \%$ & $32 \%$ & $40 \%$ & $0 \%$ & $28 \%$ \\
\hline
\end{tabular}

* Percentages are based on the total number of motion verbs in each language.

It is observed that Mandarin Chinese at the time of A Dream of Red Mansions' publication, some 130 years before its reformation in 1919, is a very pro-Verb-framed language (the percentage of its V: manner is even lower than that in Turkish), with its path verbs amounting to 49\% (compared with its 27\% uses in English and 59\% uses in Turkish). And its strong tendency to adopt V: neutral is also conspicuous. Apart from that, another noteworthy point lies in its predominant uses of $\mathrm{V}$ : deixis (59\% in our sample). However, after its reformation in 1919, Modern Chinese underwent a tremendous change both in its morphology and grammar. In order to present an overall picture of how Modern Chinese looks, we list the data as follows, which is based on the above-mentioned other four sub-samples:

TABLE 4

Percentage of Motion Verb Use in Brown's and Mao's Sample

\begin{tabular}{|l|l|l|l|l|l|}
\hline & V: manner & V: path & V: neutral & $\begin{array}{l}\text { V+V: manner } \\
(\mathbf{s u b})\end{array}$ & V: deixis \\
\hline Brown (E) & $65 \%$ & $15 \%$ & $18 \%$ & $2 \%$ & $2 \%$ \\
\hline Zhu etal (C) & $50 \%$ & $15 \%$ & $35 \%$ & $0 \%$ & $20 \%$ \\
\hline Mao (C) & $50 \%$ & $23 \%$ & $27 \%$ & $0 \%$ & $47 \%$ \\
\hline Shapiro (E) & $51 \%$ & $20 \%$ & $21 \%$ & $8 \%$ & $24 \%$ \\
\hline
\end{tabular}

* Percentages are based on the total number of motion verbs in each language. The number " $E$ " and " $C$ " as in Brown (E) and Mao (C) indicate the language concerned.

To illustrate their respective patterns as shown in Table 3 and 4, we generate the following graph for comparison (a 2\% usage in English as suggested in Da Vinci Code is assumed to be within normality). 
GRAPH 1

Motion Event in Different Languages

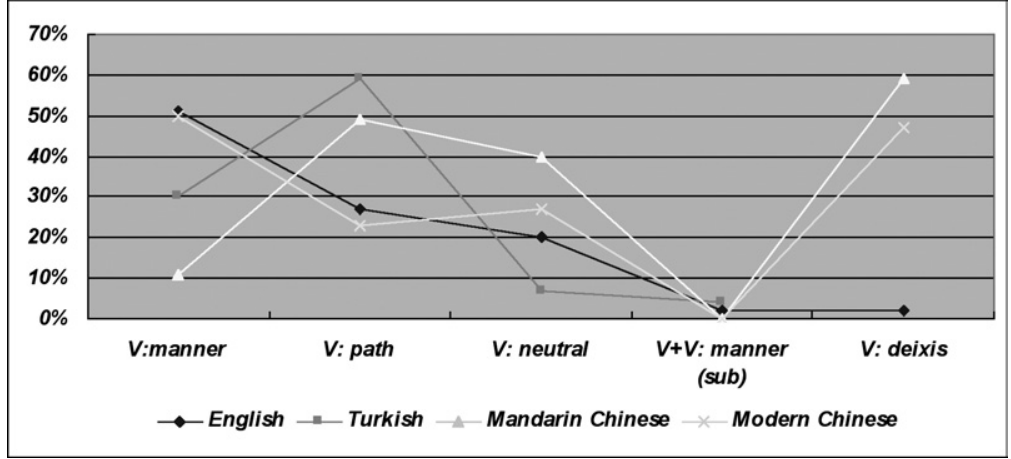

Not surprisingly, Modern Chinese (represented by Mao[C]) as shown in the Graph 1 reveals a pro-Satellite-framed-language tendency, with its $50 \%$ use of manner verbs, as discussed before by Talmy (2000), Shen (2003) and Slobin (2004a). Its uses of $\mathrm{V}$ : neutral is less conspicuous than our previous data concerning Mandarin Chinese before its reformation (represented by Chinese 1/2). But it is still characterized by an abusive use of $\mathrm{V}$ : deixis (47\% in Mao's work compared with $2 \%$ in Brown's). (In Chinese, deixis seems to be more closely tied to conception of path. This is suggested by the fact that most native speakers add a final 'come' or 'go' verb, filling standard serial-verb construction type, as in 跳进去[tiao4 jin4 qu4] 'jump enter go').

After we have a more perceptive understanding of the difference between Chinese before and after reformation (for convenience's sake, hereinafter we call the former Mandarin Chinese and the latter Modern Chinese), now we can start to analyze the data we have collected from A Dream of Red Mansions and its sets of translations.

\subsubsection{The source text effect}

As shown in Graph 2, it is self-evident that both Hawkes \& Minford's and Yang's sets of translations reveal a similar different-from-English pattern: they show a conspicuous pro-Mandarin-Chinese tendency. Compared with Ozcaliskan \& Slobin's findings, the sets of English translations are lower in V: manner (far below 51\%), but higher in V: path (all above 27\%), V: neutral (far above 20\%) and V: deixis (far above $2 \%)$. The only exception lies in the use of $\mathrm{V}+\mathrm{V}$ : manner (sub), which, to some extent, could be attributed to Chinese being morphologically unmarked.

It is worth noting that Yang, who has been educated in Modern Chinese context rather than Mandarin Chinese, shows a seemingly consistent change in his use of manner verbs, path verbs and neutral verbs with the other two English translators. 
GRAPH 2

\section{Motion Event in Sets of Translations}

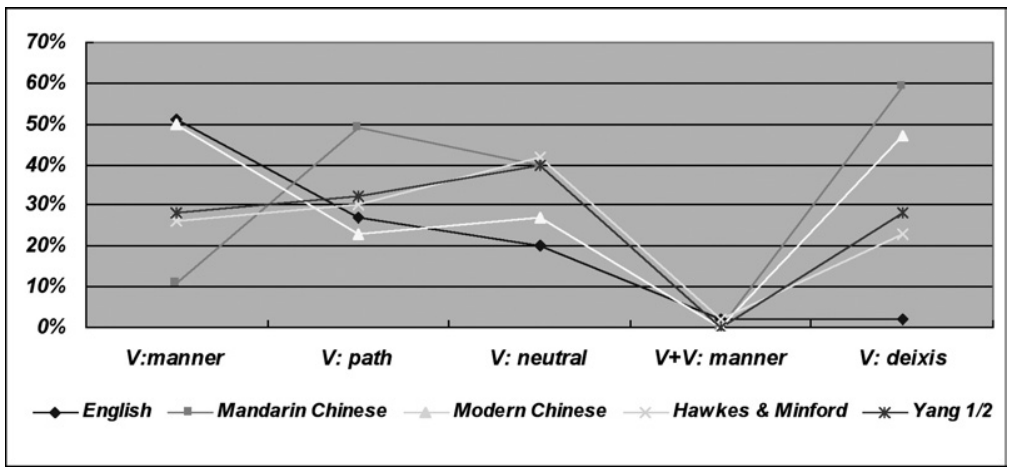

In general, the above-mentioned distortions, as we could observe in both Hawkes \& Minford's and Yang's sets of translations, thus could only be accounted for by the strong effect imposed by the source text.

Allowing for the change in Modern Chinese itself, it is also easy to understand why such consistent difference is not revealed in Shapiro's translation, with the only exception of V: deixis (24\%), which remains unchanged in Chinese before or after reformation.

\subsubsection{The translator effect}

Gentzler (2003) once claimed, "inescapable infidelity is presumed as a condition of the process; translators do not work in ideal and abstract situations nor desire to be innocent, but have vested literary and cultural interests of their own, and want their work to be accepted within another culture. Thus they manipulate the source text to inform as well as to conform to the existing cultural constraints."

Such infidelity could also be easily detected here. In our sample, among the three translators, Yang's translation tops the other two by a relatively higher margin (5\%) in terms of the use of V: deixis, which could easily be explained by the translator's Chinese linguistic background. And at the same time, no use of V+V: manner (sub) is obtained in Yang's data, which differs not so much but so significantly from Hawkes and Minford's $2 \%$ usage. Judging from their respective performances, we are certain that translators are not "innocent" in their translating, and literary and cultural interests of their own are imbued into the target text.

\subsubsection{Culturally typological difference across sets of translations}

Both the source text effect and the translator effect disclose to us there exit some latent differences underlying sets of translations as a result of the translators' being from different cultural backgrounds. Just because English and Modern Chinese both belong to satellite-framed languages, such culturally typological differences are hard to trace. In wake of this observation, it could be predicted that a translator, who are educated in a verb-framed language context, would reveal more huge typological differences in translating A Dream of Red Mansions into English.

In the following, we will keep tracing these latent cultural differences as shown in the different Motion event components. 


\subsection{Alternative lexical means}

In terms of the use of alternative lexical means, Ozcaliskan and Slobin (2003: 266) conclude that Turkish and English novels both make fairly frequent use of alternative lexical means of conveying manner, with Turkish productions showing a higher amount of use, an overall total of 107 uses in English to 113 in Turkish. And Chen's (2005: 88) findings indicate that the corresponding number in Chinese nine novels is 102. However, there is an obvious flaw in basing one's conclusion on such simple number-counting without any other reference: It can't serve as a starting point for comparison between different samples.

In the following table, we intend to provide a percentage analysis of our data, with the total number of Motion-event clauses as the denominator (see 2.1 Sample). It should be noted that the other two similar studies, which are based on Brown's and Mao's work, are also included for reference.

TABLE 5

Alternative lexical means in each sub-sample

\begin{tabular}{|l|l|l|l|l|l|l|l|}
\hline & Chinese1/2 & H \& M & Yang1/2 & Brown & Zhu etal & Mao & Shapiro \\
\hline Adv \&Des & 65 & 39 & 23 & 14 & 26 & 37 & 15 \\
\hline Percentage & $31 \%$ & $28 \%$ & $16 \%$ & $17 \%$ & $35 \%$ & $30 \%$ & $17 \%$ \\
\hline \multirow{2}{*}{$\begin{array}{l}\text { V: manner } \\
\text { Together }\end{array}$} & 6 & 16 & 7 & 12 & 8 & 20 & 10 \\
\cline { 2 - 8 } & $9 \%$ & $41 \%$ & $30 \%$ & $86 \%$ & $31 \%$ & $54 \%$ & $67 \%$ \\
\hline
\end{tabular}

* Percentages are based on the total number of Motion-event clauses in each source text and its translation. "V: manner Together" refers to the number of Adverbials \& Descriptions which are employed to elaborate or augment the manner that has already been encoded by the verb and its percentages are based on the total number of "Adv \& Des."

The above data suggests a possible equal fancy (31\% in Chinese $\mathbf{1 / 2}$ and $30 \%$ in Mao respectively) taken by Chinese towards the heavy use of adverbials and descriptions in the Motion event. However, a further analysis on "V: manner Together" reveals a tremendous difference between Chinese before and after reformation: a respective 9\% and 54\% usage of alternative lexical means is employed to elaborate or augment the manner verbs. It further justifies a two-way split between a Pro-Verb-framedlanguage Mandarin Chinese and a Pro-satellite-framed-language Modern Chinese, because Ozcaliskan \& Slobin conclude that “Turkish (a Verb-framed language) speakers use these means mainly to add manner information to basic motion event descriptions, apparently compensating for what they cannot easily encode at the level of motion verb constructions," while "English (a Satellite-framed language) speakers use such means predominantly to elaborate or augment the manner that has already been encoded by the verb." (Ozcaliskan and Slobin 2003: 268) (In our data, 86\% of alternative lexical means in English are employed for this elaboration purpose.)

In our forthcoming analysis, we will focus on two aspects of alternative lexical means, i.e., its usage and the purpose underlying.

\subsubsection{The source text effect}

In Table 3, we noted considerably less use of $\mathrm{V}$ : manner and larger adoption of $\mathrm{V}$ : path and V: neutral in Mandarin Chinese. Based on these facts, it could be assumed 
that more alternative lexical means would be employed in Mandarin Chinese, so as to compensate the manner information, which could not be encoded in $\mathrm{V}$ : path and V: neutral.

Convincingly, we could find in Table 5 that both Mandarin Chinese and Hawkes $\&$ Minford show a relatively higher usage of alternative lexical means (31\% in Chinese $\mathbf{1 / 2}$ and $28 \%$ in $\mathbf{H} \& \mathbf{M})$. Subject to the source text effect, Hawkes \& Minford surpass both Brown's and Shapiro's sub-samples by $11 \%$. But to our surprise, Yang's translation seems to be immune from this effect (an at least 30\% usage is expected here). A close look at his translation (see Table 6) discovers that Yang chooses to replace all those lexical means with manner verbs to the greatest extent, sometimes even at the expanse of the original meaning. (With due respect to the translators, we by no means intend to defame or try to evaluate the sets of translations. It is for our analysis' sake that we conduct such a comparison.) The effect of such treatment could also be observed in Yang's comparatively higher usage of manner verbs: 28\% by Yang to $26 \%$ by Hawkes \& Minford (see Table 3).

TABLE 6

Several Examples from H \& M's and Yang's Translations

\begin{tabular}{|c|c|c|c|}
\hline Chapter & Source text & $H \& M$ & Yang \\
\hline 1 & $\begin{array}{l}\text { 说说笑笑来至峰下 } \\
\text { while chatting and smiling came } \\
\text { to the foot of the Peak }\end{array}$ & $\begin{array}{l}\text { when they arrived at the } \\
\text { foot of Greensickness } \\
\text { Peak }\end{array}$ & $\begin{array}{l}\text { they came up to the } \\
\text { Stone }\end{array}$ \\
\hline 1 & $\begin{array}{l}\text { 同那道人飘然而去 } \\
\text { with the Taoist in a facile and } \\
\text { graceful way went away }\end{array}$ & $\begin{array}{l}\text { and set off at a great } \\
\text { pace with the Taoist }\end{array}$ & $\begin{array}{l}\text { and } \frac{\text { hurried off with }}{\text { the Taoist }}\end{array}$ \\
\hline 3 & $\begin{array}{l}\text { 款款散去 } \\
\text { in a jogtrotting way dispersed }\end{array}$ & and then tiptoed out & and slipped out \\
\hline 17 & $\begin{array}{l}\text { 信步来至厅上 } \\
\text { aimlessly came to the hall }\end{array}$ & $\begin{array}{l}\text { without realizing it he } \\
\text { was drifting towards the } \\
\text { main reception hall }\end{array}$ & $\begin{array}{l}\text { until he found } \\
\text { himself by the front } \\
\text { hall }\end{array}$ \\
\hline 107 & $\begin{array}{l}\text { 就一溜烟如飞的出去了 } \\
\text { like a puff of smoke swiftly went } \\
\text { out }\end{array}$ & $\begin{array}{l}\text { the guests vanished like } \\
\text { a puff of smoke }\end{array}$ & $\begin{array}{l}\text { the guests were } \\
\text { desperate to extricate } \\
\text { themselves }\end{array}$ \\
\hline 117 & $\begin{array}{l}\text { 宝玉一溜烟回到自己房中 } \\
\text { Baoyu like a puff of smoke } \\
\text { returned to his room }\end{array}$ & $\begin{array}{l}\text { he was back in his room } \\
\text { like a flash }\end{array}$ & $\begin{array}{l}\text { he streaked back to } \\
\text { his room }\end{array}$ \\
\hline
\end{tabular}

With regard to the purpose of such usage, Table 5 indicates that only $9 \%$ alternative lexical means in Mandarin Chinese are used for elaboration purpose. And not surprisingly, Hawkes \& Minford's and Yang's uses of alternative lexical means could also be affected. Their respective uses of alternative lexical means (41\% and 30\%) are both significantly less than that in the Brown's (86\%) and Mao's sub-samples (54\%). Such downward movement could only be attributed to the influence resulting from Mandarin Chinese.

\subsubsection{The translator effect}

As we have just explained, the usage of alternative lexical means reveals to us a different picture, where we could perceive the visibility of translators $(28 \%$ in Hawkes 
and Minford to $16 \%$ in Yang), but such translator's effect could be hardly recoursed to their different cultural backgrounds. It is rather a reflection of translator's individuality.

However, in terms of different purposes to adopt these alternative lexical means, Hawkes \& Minford's translations overtake Yang's by $11 \%$ in an attempt to augment or elaborate the manner of motion, which clearly indicates a different tendency to employ alternative lexical means. Such difference in tendency is best explained by the translators' different cultural backgrounds.

Again, we observe a clear culturally typological difference across sets of translations, with the exception of Yang's immunity concerning the usage of alternative lexical means.

\subsection{Path}

In the previous studies, we have noted that path particles are not taken into consideration. Obviously, this is because they have based their studies on analyzing these languages according to different typological classifications. In this way, a satelliteframed language will feature more path particles than a verb-framed one. In view of this, to some degree, whether less or more path particles appear in one language indicates a correspondingly different Motion-event framework.

As suggested below, in terms of path particles usage, Mandarin Chinese could be regarded as a typical Verb-framed language, with $26 \%$ usage per clause, while Modern Chinese stands between (70\%), compared with a $100 \%$ usage of path particles in English.

TABLE 7

Path in each sub-sample

\begin{tabular}{|l|l|l|l|l|l|l|l|}
\hline & Chinese1/2 & H \& M & Yang1/2 & Brown & Zhu etal & Mao & Shapiro \\
\hline Path & 54 & 135 & 96 & 84 & 70 & 74 & 90 \\
\hline Percentage & $26 \%$ & $96 \%$ & $66 \%$ & $100 \%$ & $80 \%$ & $70 \%$ & $101 \%$ \\
\hline
\end{tabular}

* Percentages are based on the total number of Motion-event clauses in each translation.

The source text effect is obvious here. Due to the influence from Mandarin Chinese, which employs less path particles, Hawkes and Minford's and Yang's translations are consistent in adopting less path particles (96\% and 66\% respectively), compared with their standard usage of $100 \%$ and $70 \%$ as shown respectively in Brown's and Mao's sub-samples.

Meanwhile, the translators of sets of translations demonstrate a striking difference in using path particles. Hawkes \& Minford leaves Yang behind by a 30\% discrepancy, which complies well with the tendency to use path particles in their own cultural backgrounds.

As a result, we note the same culturally typological difference between sets of translations as we expected. 


\subsection{Figure}

Figure is also absent in the previous studies. For our research purpose, here we distinguish the explicit Figure from implicit one. It is the explicit Figure that we just include here. For example, the implicit subject “宝玉 (Baoyu)” in Chinese “方出来见 贾母” ([Baoyu] went off to his grandmother's), the implicit logical subject “he” in English dangling participle "Jumping happily, he clapped his hands and chanted" are not counted as one. It is believed that the use of implicit Figure also underlies typologically conceptual differences.

TABLE 8

Figure in each sub-sample

\begin{tabular}{|l|l|l|l|l|l|l|l|}
\hline & Chinese1/2 & H \& M & Yang1/2 & Brown & Zhu etal & Mao & Shapiro \\
\hline Figure & 110 & 124 & 120 & 78 & 57 & 60 & 83 \\
\hline Percentage & $53 \%$ & $88 \%$ & $83 \%$ & $93 \%$ & $66 \%$ & $57 \%$ & $93 \%$ \\
\hline
\end{tabular}

* Percentages are based on the total number of Motion-event clauses in each translation.

In general, though both Chinese and English belong to the same typological framework, it seems that Chinese tends to use less explicit Figures than English (57\% in Mao versus 93\% in Brown). It could be argued that the grammatically different use of subject in Chinese and English have contributed to this typological difference. But what underlies the same remains unsettled and awaits further studies.

At the same time, a consistent source effect could be observed here. Both Hawkes \& Minford's and Yang's translations fall a bit short of their English counterparts (93\% both in Brown's and Shapiro's sub-samples) as a reflection of less use of Figures in the Chinese source text (57\%). As for translator effect, Yang produces less use of Figures compared with Hawkes \& Minford (83\% versus $88 \%$. In view of their respective cultural backgrounds, this is well in compliance with our predication.

\subsection{Ground and Segment}

Finally we come to analyze what happens to ground and segment. Their data are shown as follows:

TABLE 9

Ground in each sub-sample

\begin{tabular}{|l|l|l|l|l|l|l|l|}
\hline & Chinese1/2 & H \& M & Yang1/2 & Brown & Zhu etal & Mao & Shapiro \\
\hline Ground & 81 & 77 & 52 & 67 & 77 & 62 & 57 \\
\hline Percentage & $39 \%$ & $55 \%$ & $36 \%$ & $80 \%$ & $89 \%$ & $59 \%$ & $64 \%$ \\
\hline
\end{tabular}

* Percentages are based on the total number of Motion-event clauses in each translation. 
TABLE 10

Segment in each sub-sample

\begin{tabular}{|l|l|l|l|l|l|l|l|}
\hline & Chinese1/2 & H \& M & Yang1/2 & Brown & Zhu etal & Mao & Shapiro \\
\hline Segment & 209 & 161 & 157 & 84 & 87 & 105 & 89 \\
\hline Percentage & & $130 \%$ & $133 \%$ & $104 \%$ & & & $118 \%$ \\
\hline
\end{tabular}

* Percentages are based on a ratio between Chinese and English, with the latter being a denominator.

Based on the data we have collected, it seems that less ground references are made in Mandarin Chinese both before and after reformation (39\% and 59\% respectively), as most of us have been assuming. And the source effect and the translator effect are also looming behind (as indicated by $\mathrm{H} \&$ M's 55\% and Yang's 36\%). But the picture is far from clear. In Brown's and Mao's samples, the data present to us a paradox which calls for a plausible explanation before we claim the above. In this view, Chen's conclusion that "Chinese writers made sparse references to ground elements in individual clasuses" (Chen 2005: 92) shall be treated with caution and more meticulous researches are expected to find the truth out.

As for clause segmenting, Chen's claim that "Chinese writers tended to break a complex path into several segments and presented them by means of a series of action clauses" (Chen 2005: 92-93) could be optimistically accepted, as we could observe from Table 10 and Table 7 that in expressing the same conceptual notion of Motion event, Chinese tends to use more clauses (the ratio of Chinese clause to English one is ranging from 1.04 to 1.33 ) and resultingly less path particles.

\subsection{Summary}

After we have discussed all semantic categories concerning Motion event, we are in a more convincing position to announce that there exist culturally typological differences between Hawkes \& Minford's and Yang's translation works, which could be analyzed in terms of the source text effect and the translator effect. In the following three graphs, we present a collection of the above analysis.

\section{GRAPH 3}

The source and translator effect in $\mathrm{H} \&$ M's translations

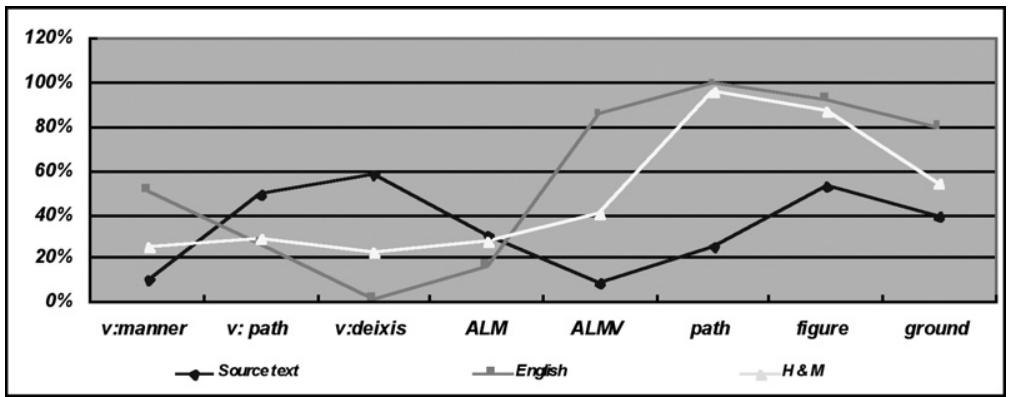

* ALM and ALMV respectively stand for Alternative Lexical Means and V: manner Together. 
GRAPH 4

The source and translator effect in Yang's translation

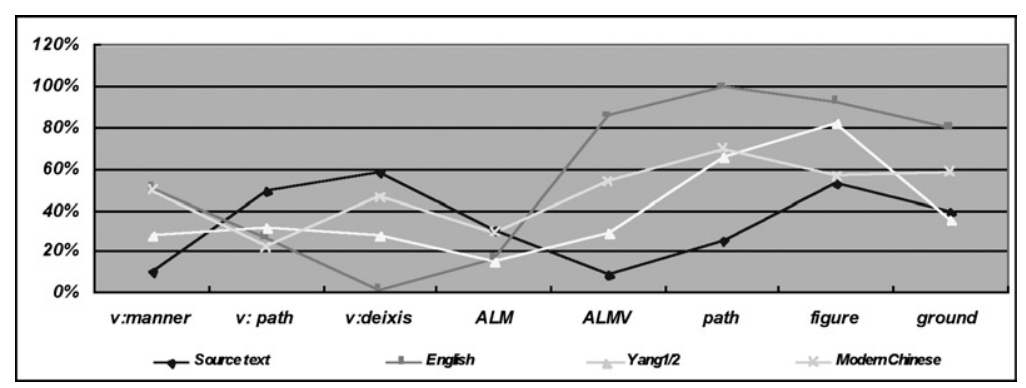

* ALM and ALMV respectively stand for Alternative Lexical Means and V: manner Together.

We could see from Graph $3 \& 4$ that the source text effect and the translator effect are intertwined. Furthermore, $\mathrm{H} \&$ M's translations stand generally between English (the native language of the translators) and Mandarin Chinese (the language used in the source text), and depict a systematic change in terms of all semantic categories of Motion event; while Yang's translation almost discloses the same systematic pattern as Hawkes and Minford's, it appears more complicated under the influence of Modern Chinese.

\section{GRAPH 5}

The culturally typological difference between sets of translations

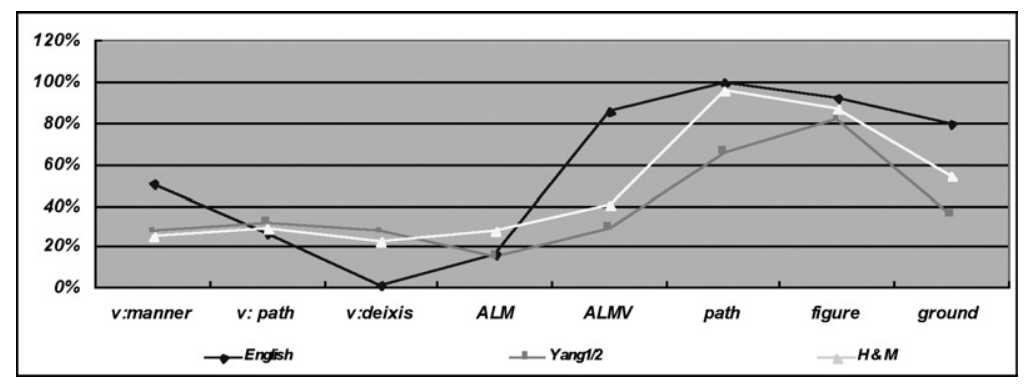

In the above graph, we could observe that compared with English, the sets of English translations show a consistent change in all semantic respects. And at the same time, from Graph 5, we could observe a culturally typological difference existing between sets of translations, especially in terms of V: deixis, Alternative lexical means, V: manner Together, Path, Figure and Ground.

\section{Conclusion}

In this study, in order to compare the encoding of Motion events across different translations, we necessarily identify and categorize the range of concepts and linguistic devices pertinent to this domain. Clearly, more is involved than verbs and particles. Border-crossing path particles or verbs could be further included here for analysis. Moreover, apart from Motion event, more linguistic categories could be added so as to ensure a more comprehensive picture. 
As for the study itself, we cautiously avoid the problem arising from the different versions of the source texts adopted by Hawkes \& Minford and Yang, which, if taken into account, would impose certain effects on our sampling, but little on our analysis.

Again, we don't include those clauses left untranslated in sets of translations (7 clauses left untranslated for $\mathrm{H} \& \mathrm{M}$ while 8 for Yang in our samples). As claimed by Ana Rojo and Javier Valenzuela (2001), translators tend to supply additional information which has been taken from their evaluation of the global interactional frame, regardless of the verb used. These "translation shifts" (deletions and additions), as they are termed, has to be left untreated in our analysis.

And at the same time, the reference data in Brown's and Mao's sample we have often turned to is based on a relatively small corpus as a result of lacking relevant findings. A more convincing and reliable figure is expected based on a larger and more comprehensive collection of samples.

Notwithstanding the above limitations, we have explored into the culturally typological difference across sets of translations of the same work, in the same language but of different versions, by analyzing its apparent source text effect as well as translator effect in a more plausible and foreseeable way. By means of Motion event, we first turn Wang's observation, Hatim's suggestion and Baker's hypothesis into reality and testify its feasibility; second, we avoid more subjective speculations or exemplar presentations in the similar studies and attempt to base our findings on more objective observations, so as to reveal what is underlying "the text embedded in its network of both source and target cultural signs" (Bassnett and Lefevere 1990).

Moreover, by analyzing cultural effects underlying sets of translation from a linguistic perspective, we anticipate opening a new horizon for more similar research along this line. As Bhabha claims full of anticipation, "from the little pieces of the poem, its going and coming, there rises the great history of languages and landscapes of migration and diaspora. (Bhabha 2004[1994]: 337)" in its literal sense, we sincerely hope Motion event, this "little" linguistic category, could do the same to partly reveal to us the landscapes of how culture is translated through source text and by the translator.

\section{NOTES}

1. The author wishes to thank Professor Wang Ning for his extensive contributions to the conceptualization of this article as well as for his advice and help in the analysis. The author also extends grateful acknowledgement to the helpful comments from Anaïs Tatossian.

2. See $h t t p: / / n e w s . x i n h u a n e t . c o m / n e w s c e n t e r / 2005-04 / 18$ content $284019 . \mathrm{htm}$.

3. A Dream of Red Mansions is written by Cao Xueqin and Gao E in the 18th century during the Qing Dynasty. As a classic literary work, it represents the most sophisticated and expressive form of Vernacular Chinese (白话文) in ancient China, where Literary Chinese (文言文) has always been assuming a predominant role in literary writings. It is not until 1919 that Vernacular Movement has turned against the use of Literary Chinese and thrown China into an era of Vernacular Chinese, the precedent of Modern Chinese. Yang's translation work started from the early 1960s and was published between 1978-80 while Hawkes \& Minford's work was published between 1973-1986.

4. Spring Silkworms and Other Stories is a selection of short novels written by Mao Dun (茅盾) (18961981), one of the most revered Chinese authors of the 20th century, standing in the ranks of Lu Xun(鲁迅), Ba Jin(巴金) and Guo Moruo(郭沫若) and this work has been translated into English in 1956 by Sidney Shapiro, a former New Yorker born in 1915, who graduated from the Faculty of 
Law at St. John's University in 1937, was recruited into the army and was arranged later to study Chinese during the World War II, and has resided in China since 1947.

5. The Da Vinci Code is the best selling thriller by Dan Brown, translated into Chinese in 2004 by Doctor Zhu Zhenwu and others.

6. As for the definition of "clause" in Chinese, there is no definite conclusion among the Chinese scholars. Here we compare Li Jingxi (1992 [1924], Chao Yuanren (1968), Zhu Dexi (1981) and Xing Fuyi (1997) with Wang Li and Liu Shuxin. The latter's suggestions are more feasible and easier to operate on.

\section{REFERENCES}

BAKer, M. (1993): "Corpus Linguistics and Translation Studies: Implications and Applications," in Baker, M., Francis, G. and E. Tognini-Bonelli (eds.), Text and Technology: In Honour of John Sinclair, Amsterdam/Philadelphia, John Benjamins.

Bassnett, S. and A. Lefevere (2001): Constructing Cultures: Essays on Literary Translation, Shanghai, Foreign Language Education Press.

Berman, R.A. and D.I. Slobin (1994): Relating Events in Narrative: A Crosslinguistic Developmental Study, Hillsdale, Lawrence Erlbaum Associates.

Bнавна, H. K.(2004): The Location of Culture, London and New York, Routledge.

Brown, D. (2003): The Da Vinci Code, New York, Doubleday.

Brown, D. (2004): 达芬奇密码 (The Da Vinci Code), translated by Zhu, Z.W., Wu, C., Zhou, Y.X. Shanghai, Century Publishing Group.

CaO, X. Q., and E. Gao (1973-1986): The Story of the Stone, translated by Hawkes, D. and J. Minford, London, Penguin Books.

CAO, X. Q., and E. GAO (1996): 红楼梦 (Hong Lou Meng), Beijing, People's Literature Publishing House.

CAO, X. Q., and E. GAo (2001): A Dream of Red Mansions, translated by YAnG, X.Y. and G. YANG, Beijing, Foreign Languages Press.

Chen, L. (2005): The Acquisition and Use of Motion Event Expressions in Chinese, unpublished doctoral dissertation, University of Louisiana at Lafayette.

Gennari, S. P., Sloman, S.A., Malt, B.C. and W.T. Fitch (2002): "Motion Events in Language and Cognition," Cognition 83-1, pp. 49-79.

Gentzler, E. (2003): Contemporary Translation Theories, Shanghai, Foreign Language Education Press.

GoldBerg, A. E. (1998): "Patterns of experience in patterns of language," in Tomasello, M. (ed.), The New Psychology of Language, Mahwah, Lawrence Erlbaum Associates.

Натім, B. (2005): Teaching and Researching Translation, Beijing, Foreign Language Teaching and Research Press.

IxbarRetXe-Antuñano, I. (2004): "Language Typologies in our Language Use: The Case of Basque Motion Events in Adult Oral Narratives," Cognitive Linguistics 15-3, pp. 317-349.

LiU, S. X. (2002): 现代汉语理论教程 (Course of Modern Chinese Grammar), Beijing, High Education Press.

MaO, D. (1979): Spring Silkworms and Other Stories, translated by Shapiro, S., Beijing, Foreign Languages Press.

Mao, D. (2001): 茅盾小说 (Mao Dun Readers), edited by Fu, G. M., Hangzhou, Zhejiang Arts and Literature Publishing House.

Mcneill, D. (2000): "Analogic/Analytic representations and cross-linguistic differences in thinking for speaking," Cognitive Linguistics 11-1/2, pp. 43-60.

Narasimhan, B. (2003): “Motion events and the lexicon: a case study of Hindi," Lingua 113, pp. 123-160.

Neubert, A. and G. M. Shreve (1992): Translation as Text, Kent, The Kent State University Press.

Он, K. J. (2003): Language, Cognition, and Development: Motion Event in English and Korean, unpublished doctoral dissertation, University of California, Berkeley. 
Ozcaliskan, S. (2005): "Metaphor meets typology: Ways of moving metaphorically in English and Turkish," Cognitive Linguistics 16-1, pp. 207-246.

Ozcaliskan, S. and D. I. Slobin (2003): "Codability Effects of the Expressions of Manner of Motion in Turkish and English," in Taylan, E.E.. and S. Ozsoy (Eds.), Proceedings of the Tenth International Conference on Turkish Linguistics, pp. 259-270.

Rojo, A. and J. Valenzuela (2001): "How to Say Things with Words: Ways of Saying in English and Spanish," Meta 46-3, pp. 467-477.

SHEN, J.X.(2003). 现代汉语 “动补结构” 的类型学考察 (A Typological Analysis on Verb + Complement Structure in Modern Chinese), Chinese Teaching across the World 3, pp. 17-23.

Slobin, D. I. (1996): "Two ways to travel: Verbs of motion in English and Spanish," in Shibatani, M. and S. A. Thompson (eds.), Grammatical constructions: Their Forms and Meaning, Oxford, Clarendon Press.

Slobin, D. I. (1997): "The universal, the typological, and the particular in acquisition," in Slobin, D. I. (ed.), The Crosslinguistci Study of Language Acquisition, Vol.5.: Expanding the contexts, Mahwah, Lawrence Erlbaum Associates.

SLOBIN, D. I. (2004a): "The many ways to search for a frog: Linguistic typology and the expression of motion events," in StrömQvist, S. and L. Verhoeven (eds.), Relating Events in Narrative: Vol. 2. Typological and contextual perspectives, Mahwah, Lawrence Erlbaum Associates.

Slobin, D. I. (2004b): "Relating Narrative Events in Translation," in Ravid, D. and H. B. Shyldkrot (eds.), Perspectives on Language and Language Development: Essays in Honor of Ruth A. Berman, Dordrecht, Kluwer.

Slobin, D. I. (2005): "Linguistic representations of motion events: What is signifier and what is signified," in Maeder, C., Fischer, O. and W. Herlofsky (eds.), Iconicity Inside Out: Iconicity in Language and Literature 4, Amsterdam/Philadelphia, John Benjamins.

Stromevish, S. and L. Verhoeven (2004): "Relating events in narrative: Typological and contextual perspectives," Mahwah, Lawrence Erlbaum Associates.

Talmy, L. (1985): "Lexicalization patterns: Semantic structure in lexical forms," in SHopen, T. (ed.), Language Typology and Lexical Description: Vol. 3. Grammatical categories and the lexicon, Cambridge, Cambridge University Press.

Talmy, L. (2000): Toward a cognitive semantics: Vol. II: Typology and Process in Concept Structuring, Cambridge, MIT Press.

WANG, L. (1985): 中国现代语法 (Chinese Modern Grammar). Beijing, Commercial Publishing House.

WANG, N. (2006): 文化翻译与经典阐释(Cultural Translation and Elaboration on Canon Works). Beijing, China Publishing House.

XU,. J. and X. Y. YuAn (2001). 当代法国翻译理论 (Contemporary Translation Theories in France), Wuhan, Hubei Education Publishing House. 